\title{
Criminology Analysis from the Perspective of Chinese Ancient Materialism
}

\author{
Peng Wang \& Jingyi Wang \\ Criminal Justice law School \&Economic Law School \\ East China University of Political Science and Law \\ Shanghai 201620, China \\ Tel: 86-21-3355-2568 E-mail: wangpenghuazheng@163.com
}

\begin{abstract}
Crime problems arise from social system, which demand systematic solutions. The Ancient Chinese Yin and Yang theory and "Five Elements" attach importance to the overall mode of thinking, attaches importance to grasp object from overall aspect. Taking precautions against and controlling crimes by applying this thought, can able to help us to analyze crime problems in depth. Use system method to resolve the system problem.
\end{abstract}

Keywords: "Five Elements", "Yin and Yang", System thought, Crime problems

Crime problems, which arise from large-scale social systems of civilization, are influenced and controlled by the law of social systems, and work with a systematic form. Factors that influence the system of crime problems are various and bear a subtle connection. How to deal with crime problem determines how to prevent and to control them. The ancient Chinese philosophy "Yin and Yang" ("Yin and Yang", is regarded as the most basic and the most widespread philosophy category in the Chinese philosophy history, which illustrates the contradictory movement of the related thing as well as the law of development.) and "Five Elements" ("Five Elements", is the important concept in Chinese philosophy history, which is five kind of symbolic marks, refers to the gold, the water, the wood, the fire, the earth.) theory, concentrate on the relationship among various factors in the Yin and Yang system and Five Elements system, focusing on the integration of systems thinking and the overall grasp of things. This emphasizes the structure and functions of things, and forms Chinese people's unique system of thinking. This is obviously a very systematic description of the crime problems, which can provide a deep understanding of crime issues. Taking our ancients' thoughts into consideration, appropriate analysis of the large-scale system of society and construction of "Yin and Yang" and "Five Elements" structure in crime case system have become the key points of prevention and control in crime case system. This thesis introduces ancient theories of "Yin and Yang" and "Five Elements" into prevention and control of crime problems, makes the past serve the present and endows it with new connotation.

\section{1. "Five Elements" formation mechanism of the crime problems system}

So as to the existence of the crime problems in the system form, has common origin with theory of the five elements. It exists as a result of common logical similarity with "Five Elements", has the unified structure form. The theory of "Five Elements" in ancient China neither studies what entity in the nature is actually made from, nor inspects the specific modes of action between different things. It stresses the research of the commonest structural relation of inherent laws of things and that between them and sets up theory system about the nature by means of the concept of "Five Elements" structure. Wood, fire, earth, gold and water actually serve as signs representing five functional attributes. Crime problems are derived from this large-scale system of society and controlled by its basic rules. Therefore, in order to explore "Five Elements" models of crime problem system, we should firstly establish "Five Elements" structure of the large-scale system of society. Elements are the basic to form the system; the various elements of the system are not isolated, unrelated to each other. However, they are in mutual connection and coactions. Human society is a political, economic, cultural and natural organic entity; human civilization is composed of material civilization, spiritual civilization, political civilization, social civilization and ecological civilization, which constitute the new "Five Elements". The five elements mutual promotion and restraint between the five elements, which can be reflected in each fields of society, but the five elements assault and browbeat mutually can cause a lot of social problems, including 
crime problems.

In view of the function attribute sign in traditional Chinese medical science according to the five elements. The author thinks that, although the large-scale social systems in the form of five civilization and wood, fire, earth, gold, strict water one by one counterparts, is not entirely reasonable, it may not be scientific, but in order to better illustrate that interrelation between every element in society system, as well as the relationship between structure and function; the corresponding division in the social system according to the five key attributes of their civilization is necessary. Material civilization pays attention to the economic development with its value embodied by the form of GDP or GNP, which has gold attribute. Spiritual civilization emphasizes the intellectual production and the spiritual life. The culture, the idea may educate the human, encourage the human, similarly may also damage the human, just likes the fire may deliver warm to the human, can also set fire on the self-immolation, and therefore has the fire attribute. The political civilization emphasizes the democracy, the freedom. It just likes the big tree which stretches freely, the luxuriant growth of leaves and branches, green and luxuriant, therefore have the wood attribute. The social civilization emphasizes the society to be harmonious, just likes the earth breeding myriad things, has the earth attribute. The ecology civilization is the origin of life, the human culture survival foundation, has the water attribute.

\section{INSERT FIGURE 1 HERE}

The complicated relation between "Five Elements" displays an extremely intricate, continuously changing and metabolic process of opposite and uniformity, dependence and transformation of everything in the objective world which will never end. The five elements depend on and improve each other and also exclude and restraint each other. Such a relation in coordination contributes to the balance of everything in the universe and is able to serve people. (Liu Xiaohong, 2004, P.41). In the civilized society system, five elements of promoting and constraining mutually are the most basic relations, "To take advantage of a weak point in an opponent's defense, to use their strength to bully the weak" are derived from the promoting and constraining mutually relations. Mutual promotion of the five elements, namely help, growth, promotion meaning. Repels one another, and then contains the restraint, to constrain, the restraint meaning. The relationship of promoting and constraining mutually among the Five Elements in the civilized system is not fixed invariable, which is different from the traditional principles of Five Elements. The relationship among various elements does not have the strict mutual promotion of the five elements or repel one another, but is one kind restricts, promotes, the interdependence relations mutually. In the civilized society system, the relations of promoting and constraining mutually among Five Elements are intrinsic relations in the normal condition. They are maintaining the civilized system's normal biochemistry and the coordinated development; this is in the civilized system's "Five Elements" of systems.

Subjugation refers to attack at a weak point while counter-restriction is bully relying on one's power. (Liu xiaohong, 2004, P.128). Subjugation and counter-restriction in the large-scale system of society belongs to its abnormal phenomenon and its instable state. So-called abnormal refers to over and inferior these two situations. If "the construction of material civilization" is over, then it will restrain and ride roughshod over other elements which surpass the normal limitation. That is subjugation or counter-restriction of each other. Its appearance will cause partial unbalance in the large-scale system of society. If one element restrains more, it is necessary for an opposite force to suppress it within "Five Elements" in the system owing to the interlocking relationship of generation and restriction. For example, if "the construction of political civilization" in the system of civilization is over, other elements inferior to it will pose an opposite force on it. That is to say, political civilization construction will be multi-restricted by economical and cultural development and environmental factors. Five Elements in social system recover to a relatively balanced state through this regulating process. The abnormal large-scale system of society can be adjusted by its self-regulation mechanism and recover to balance. If this mechanism doesn't work, external forces will be needed.

\section{The analysis of "Five Elements" in crime system}

Crime come from the civilized society system and is subjected by the operation regularity of civilized system. It is also running by itself in the form of a system. "To take advantage of a weak point in an opponent's defense, to use their strength to bully the weak." in civilized system causes the regional imbalances in the civilized system, brings about a lot of anomalies, and forms a system of social problems, including crime system. "To take advantage of a weak point in an opponent's defense, to use their strength to bully the weak" in civilized system is too "material", and the other elements are lacked, which is reflected in the public security field and formed the crime system. The too much "material" does not mean the construction of material civilization is now very perfect, but the construction of material civilization in the civilized system is relatively too much. Subjugation and counter-restriction in civilized system is mainly reflected at the unhealthy development of five civilizations.

\subsection{The construction of material civilization is imperfect.}

Crime problem exists for the reason that the development of material progress goes wrong. In other words, crime problem exists systemically for economic reasons. The system of crime problem is influenced by economic considerations. Crime problem is typically embodied in the passive aspect and negativity of market economy. From the 
negative effects of the market economy, the market economy is a double-edged sword. Its competitiveness, autonomy, open, market and economy have their negative impacts and cause the crime. At present, the causes of negativity and crime of market economy are mainly in four aspects: First, focus only on economic benefits, not pay attention to the health of the economy. The socialist market essentially requires not only economic benefits, but also social benefits in the economic activities. But there are varying degrees of focusing only on economic benefits and neglecting the ecological balance, the country's stability, and social harmony in real life. Second, only focus on the economy, but not on the fair. The criminals do not enhance economic benefits according to the principle of fair competition. They even enhance their economic benefits with a breach of social and others' economic benefits. Third, focus only on the purpose, do not pay attention to the means. They do not enhance economic benefits according to the principle of unity of means and purpose. Their purpose is legitimate, but their means is illegitimate. They use non-economic means, counter-economic means, ultra-economic means and even criminal means to pursue the economic benefits unscrupulously, pursue the criminal benefits directly.

\subsection{The construction of spiritual civilization is not in place.}

The crime system reflects the construction of spiritual civilization is not in place. It mainly refers to the cultural reasons caused by the crime problems. The society lacks a sound mechanism of moral binding and the correct value orientation, which is reflected in the crime is: People are lacked of a correct understanding of power, money and favor. In real life, people have a one-sided understanding about them, such as "Money makes the mare go" and "litigation is to sue a relationship because we have to find a relationship and favor with the judge. If we have a good relationship with the judge, we will win the case. Otherwise we will lose it." The misunderstanding makes people desire money and status blindly. It easily leads to the crime. The interactions of "Power, money, favor", such as the union of power and power, power and money, power and favor, form a solid triangle at the core of "power". It has become a crime "Golden Triangle" which is difficult to be captured.

\subsection{The construction of political civilization is not complete.}

Politics is the concentrated expression of economics. The political reason of crime system is mainly that the people-oriented thinking is not implemented well. The negativity of feudal politics and power is mainly reflected in power lacking of controlling, power hampering economy and power advancing private interests. China has a feudal history of over two thousand years which led to the remaining of hierarchical mentality, privilege mentality, dictatorial mentality and separatism. These thoughts continue to influence people's ideas of the times. In addition, the exercise of power is short of effectively supervisory mechanism, so the situation of "excessive persons in authority, excessive persons in residual power, excessive persons in exchanging power and excessive persons in using power" appears. Power lacking of controlling creates problems of economic cases; power hampering economy causes that various entitlements get excessively involved in economic activities and generates "power economy, approved-document economy and message economy"; at the same time, economic sectors get excessively involved in administrative practice; power advancing private interests leads to such abnormal ideas as "Good Fortune for Power", which have been agreed by the person in authority. Those persons are guilty of corruption and accepting bribes as well as eating, drinking, and being merry. The construction of political civilization in society emphasizes people-oriented, everyone is equal. However, there are disparities among government officials, ordinary people, the government officials and ordinary people in the society. The disparity among government officials is a relationship between those in power. There is a disparity between persons of different positions. The effective supervision mechanism of power is lacked. The supervision and management of setting up, authorizing and using the power are neglected. The disparity between government officials and ordinary people is an unequal relationship between citizens and those in power. Those in power have not strictly adhered to the "people-based" thinking. In addition, there is no perfect petition system. The public supervision to officials is lacked. The disparity among ordinary people is the relationship between the citizens. People lack generous attitude, love and compassion in dealing with interpersonal relations. There is no good morality between them.

\subsection{The start of construction of ecological civilization is late.}

The birth, aging, sickness and death of human beings are natural phenomenon. The crime is also a same natural situation. Man is part of nature. In the final analysis, man's actions and conduct depend on natural conditions. Therefore, man's crime activities are conditioned by the influence of nature. The production and life of mankind are both not separated from nature. Ecological environment has a direct impact on various stage of the production and life of mankind. Moreover, the productive and life activities of mankind may affect and remake nature. To harmonize the relationship between human and nature refers to developed production, affluent life and a sound ecological environment The people's illegal and criminal activities are affected and constrained by the nature. The start of construction of ecological civilization is late in China and has not been paid enough attention, resulting in a number of ecological problems. The damage of ecological environment seriously affects people's production and life. But the lack of ecological resources further motives the criminals to violate the national laws and regulations for the predatory exploitation of ecological resources. The discord between human beings and nature easily leads to the crime. 


\subsection{The construction of social civilization is not harmonious.}

The reason why the society has a lot of social problems is the social disharmony. Various parts and elements which form the society and are in the interrelation are in the state of discord, the relationship between the interests of all parties has not been effectively coordinated, the social management system is not perfect. Social disharmony resulted in a number of unstable situation. There are many disharmony factors between human beings and society, between human beings and nature, and between people. The illegal and criminal activities on economy are generated and developed in such discord factors.

To sum up, the "Five Elements" system of crime problems is a kind of abnormal phenomenon generated by the subjugation and counter-restriction of five elements of the large-scale system of civil society. It means that "the construction of material civilization" is over and the shortage of other elements. If "the construction of material civilization" is over, then "the construction of material civilization" will restrain and ride roughshod over other elements which surpass the normal limitation. The disharmony of the overall structure of the social system, which is caused by the advanced development of material civilization of the large-scale system of civil society and the relative lag of the other civilization, brings serious gap between rich and poor and it pricks up the contradiction of the system and then engenders local instability of the large-scale system of civil society. The criminals who are facing the disharmony of the society such as the lack of harmonization of the relationships between human and human, human and society, and human and nature, as well as the temptation of money, power and sex will easily pursue the material and spiritual balance with adventure. That promotes the crime problems and engenders the "Five Elements" system of crime problems.

\section{The distinction of "Yin and Yang" in "Five Elements" system in the criminal cases}

The scientists on Yin and Yang think, there is a general connection whether the tangible objects or intangible objects in the world, whether the objects in the universe or the objects in the earth. The two sides in the conflict always display two types of opposite trends on state: One is bright, vibrant, forward, up, warm and full. Another is dark, quiet, backward, downward, cold and void. (Liu Changlin, 1999, P.283). The ancients in China called the former state Yang and the latter state Yin. Base on the "Five Elements" system in crime, under the strategic perspective, if the "Five Elements" system in crime exists, the "Five Elements" system in crime prevention and control should exist. The two systems together constitute the "Five Elements" system in criminal cases. The framework of Yin and Yang is made in the "Five Elements" system in criminal cases. Yang in practice means the "Five Elements" system in crime prevention and control. Yin in practice refers to the "Five Elements" system in crime which disrupts public order. There is a variety of game systems between the two systems, including the five dialectical relationships: the opposition of Yin and Yang, the interdependence of Yin and Yang, the waning and waxing of Yin and Yang, the transformation of Yin and Yang and the reflection of Yin and Yang.

The so-called opposition of Yin and Yang is an inter-confrontation of the strength between the two systems. The society prevents and combats crime through economic, political, cultural, ecological means, uses the strategic thinking of system to system. And the criminals will evade the police and form criminal ways of group, intelligence, science and technology to become "There are antidotes to the policies" and give tit for tat with the prevention and control system.

Crime is the contradiction of the case reaches the extreme, and will help promote the solution of social problems in time so as to push forward the development of society. Precisely because of the existence of crime system, the strength including the whole prevention and control system has the significance of existence. At the same time, the relatively weak strength of prevention and control leads to the generation and development of crime in a certain extent. This relationship which is interdependent, either party can not be divorced from the other party and stand alone, is the interdependence of Yin and Yang.

In the face of "advance with the time" criminals, only by evolving the developing concept of crime prevention and control team, combining the three defenses "People defense, material defense and technology defense" into one, summing up new methods and experiences and exploring new ideas and measures in the face of new problems and situations in the criminal field, can prevent and combat the crime effectively. Who is the winner in the relationship of Yin and Yang, depends not only on who is on behalf of justice, but also on who can truly advance with the time. As a result, Yin and Yang, the two forces, battle for wits and play tricks constantly. The Yin and Yang wan and wax each other.

There are rationality and necessity in the existence of the transformation of Yin and Yang, which depends on its own uniqueness of crime. For example, some of the bigger crimes can even prosper economy, the local governments can easily throw away the principle and only focus on the immediate interests, can not the nature of crime on the side of the country, the conversion process between police and criminals has been implemented unconsciously, such as the large smuggling of Yuanhua in Xiamen province that shocked the world.

"There is Yang within Yin, there is Yin within Yang."(Liu Changlin, 1999, P.290). Whether the prevention and control system of crime is sound can be seen from the degree of severity of crime in the society. Likewise, the economic cases 
system can be reflected from the prevention and control system of crime. The feature of reflection of Yin and Yang is from the interaction of the two systems. Yin and Yang send their messages to each other and at the same time become the recipients and storers due to the interaction.

Besides, according to the division concept of the ancients, the framework of "Yin and Yang" in "Five Elements" system of crime problems can be endlessly divided and find out "Yin and Yang" contradictions included in these two systems themselves, namely, "Yin and Yang" reappearing in "Yin and Yang". For example, especially to "Five Elements" system of crime problems, those posing serious influence on the society and requiring urgent solutions are called "Yin in Yin", while those posing less severe influence on the society are named "Yang in Yin" according to various characteristics of criminal cases and different degrees of harm to the society. As for "Five Elements" system of the prevention and control of crime problems, the system of social prevention and control which is represented by the police can take effective measures to strongly restrict crime problems by tight search. This is called "Yang in Yang". Conversely, aiming at some atypical crime problems, the system of prevention and control is not able to find apt and specific ways to solve problems and to effectively prevent or control because of its atypical characteristic. This is called "Yin in Yang". Meanwhile the university of "Yin and Yang" also represents in time. Human beings are angle in one side and also devil in the other. Thoughts severely struggle in offenders' minds before, within and after carrying out their crimes, which can be named as "ebb and flow of Yin and Yang". Comparison between these two forces determines the whole process of crimes. If the side of angle surpasses devil, crimes maybe will not occur or fine transformation happens when offenders commit crimes. In a word, the ancients' systematic concept of "Yin and Yang" is uniquely superior when analyzing crime system and the master of "Yin and Yang" in "Five Elements" system of crime problems is the key point of prevention and control of crime problems.

\section{Conclusion}

Yin and Yang and "Five Elements" all focus on studying and grasping the object from the function, relationship and whole, emphasize the significance that the dynamic balance affects the normal development of things, and think the whole system possesses a certain capacity of self-regulation to maintain the dynamic balance.(Liu Changlin,1999, P.300). Logically, the structural relation of "Five Elements" in crime system can be seen as the spread of Yin and Yang relationship in the criminal case system. Any actions sent by every element in the "Five Elements" in civilization large-scale systems will of the "Five Elements" of each line to any other line, will receive a corresponding counter-action due to the mutual promotion and restraint between the "Five Elements", which makes the "Five Elements" can always maintain the system balance in the process of movement under the normal circumstances. Therefore, the mutual promotion and restraint, "to take advantage of a weak point in an opponent's defense, to use their strength to bully the weak" in "Five Elements" of the system are the particular expression of extension and of Yin and Yang relationship. The structure of Yin and Yang of crime system can be seen as a model of system. But this model is too abstract, it can not specifically explain the rich contents of system structure and multifaceted relations in many cases. The "Five Elements" structure in crime system can relatively and specifically divide that the system is a general mechanism of a complex structure relationship of things. And the Yin and Yang distinction in criminal case system is a higher sum of structure relationship in crime system.

\section{References}

$\mathrm{Hu}$, Jintao. (2007). Hold high the great banner of socialism with Chinese characteristics to win the all-round well-off society and strive for new victories - report in the seventeenth meeting of the Communist Party of China's National People's Congress.(1st ed.). People's Publishing House.

Jin, Qigao. (2006). "The cat and mouse on the peace", Journal of the Chinese People's Public Security University, $1^{\text {st }}$ in 2006.

Liu, Changlin. (1999). The Chinese thinking of system. (1st ed.). China Social Sciences Publishing House.

Liu, Xiaohong. (2004). The Mysterious Five Elements. (1st ed.). Guangxi People's Press.

Shirley, Louis. (2002) . Crime and Modernization. (1st ed. ). CITIC Publishing House.

Wang, Zhimin and Huang, Jingping. (1990). Economic Development and Changes in Crime.(1st ed.). Renmin University of China Press.

Yang, Zhengming. (2004). New Theory of Economic Crime Investigation.(1st ed.). Founder of China Publishing House.

Zhang, Qingxu and Chen, Haiyan. (2003). "In defense of Marx-Question of Crime Function Theory". Journal of Southwest University of Political Science, $6^{\text {th }}$ in 2003. 


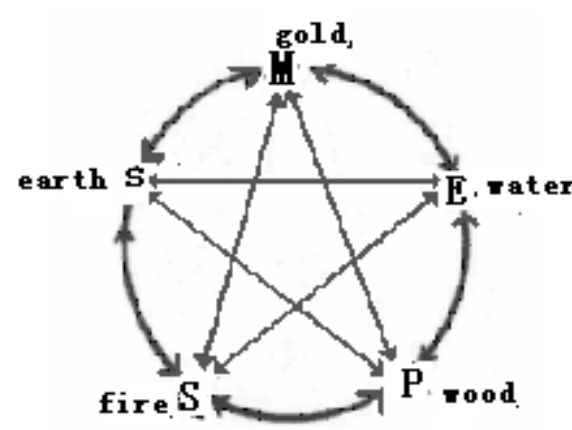

The relations of pronotes and constrains nutually in the social systen
M: Material civilization

E:Ecology civilization

$P$ :political civilization

S: Spiritual civilization s: Social civilization

Figure 1. The system of "Five Elements" 